FON ; Jurnal Pendidikan Bahasa dan Sastra Indonesia

Volume 12 Nomor 1 Tahun 2018

\title{
STRATEGI MENULIS YANG DIGUNAKAN OLEH MAHASISWA DALAM ESAI ARGUMENTATIF
}

\author{
Erwin Oktoma \\ Pogram Studi Penidikan Bahasa Inggris Fakultas Keguruan dan Ilmu Pendidikan \\ Universitas Kuningan \\ E-mail: erwin_oktoma@yahoo.com \\ Dede Rizky Amalia \\ Pogram Studi Penidikan Bahasa Inggris Fakultas Keguruan dan Ilmu Pendidikan \\ Universitas Kuningan
}

\begin{abstract}
ABSTRAK
Penelitian ini menganalisis mengenai strategi menulis yang digunakan oleh Mahasiswa dalam menulis esai argumentatif dan mengetahui masalah-masalah yang dihadapi oleh para Mahasiswa dalam menulis essay argumentatif berdasarkan teori McLean (2012), ada beberapa strategi menulis yang akan membantu para penulis ataupun para Mahasiswa terutama Mahasiswa perguruan tinggi untuk dapat menyelesaikan tugas menulis mereka dengan baik. Strategi menulis tersebut dibagi menjadi 4 langkah, seperti: menggunakan proses menulis, mengelola waktu, menetapkan tujuan, dan menggunakan sumber pengetahuan yang ada di dalam perguruan tinggi. Metode yang di gunakandalam penelitian ini adalah metode kualitatif. Berdasarkan analisis data pada mahasiswa/i kelas tiga di satu perguruan tinggi swasta di Kuningan, Jawa Barat, dapat ditarik beberapa kesimpulan. Para mahasiswa/i menggunakan lebih dari satu strategi penulisan ketika mereka menulis esai argumentatif. Strategi yang digunakan oleh para mahasiswa/i adalah kita dalam proses penulisan, pengelolaan waktu, penetapan tujuan, dan penggunaan beberapa sumber kuliah. Penelitian ini menunjukkan bahwa strategi yang paling sering digunakan oleh mahasiswa/i adalah menggunakan strategi proses penulisan $17(42,5 \%$.) Strategi ini membantu siswa dalam mengatasi keterbatasan penulisan esai argumentatif. Temuan ini juga menunjukkan strategi penulisan lainnya yang digunakan oleh mahasiswa/i, seperti, membaca lebih banyak materi, membuat draf atau garis besar, melakukan penulisan
\end{abstract}


FON ; Jurnal Pendidikan Bahasa dan Sastra Indonesia

Volume 12 Nomor 1 Tahun 2018

bebas, membuat skuad terdiri dari beberapa kotak untuk mengklasifikasikan setiap struktur esai, dan salah satu mahasiswa/i mengacu pada kegiatan terkait internet lainnya seperti membaca lebih banyak jurnal dan artikel bahasa Inggris. Strategi tersebut digunakan untuk mengatasi kesulitan mahasiswa/i dalam menulis esai argumentatif.

Kata kunci : strategi menulis, esai argumentatif

\section{PENDAHULUAN}

Dalam bidang pendidikan bahasa, keterampilan menulis adalah termasuk salah satu keterampilan berbahasa yang harus dikuasai oleh peserta didik. Keterampilan menulis menuntut kemampuan yang kompleks walaupun untuk menuliskan sebuah karangan sederhana sekalipun.

Menulis dalam bahasa asing tampaknya menjadi keterampilan bahasa yang paling sulit untuk dipelajari oleh Mahasiswa yang berada di negara yang mempelajari bahasa asing tersebut. Menulis sangat jarang di praktekan oleh Mahasiswa di dalam proses pembelajaran karena kegiatan menulis dianggap sebagai kegiatan yang paling kompleks. Seperti cara kita sedang berpikir, menulis membutuhkan waktu untuk mencapai titik yang dimaksudkan sebelum menghasilkan hasil yang memuaskan. Tuan (2010) berpendapat bahwa menulis dalam bahasa Inggris, untuk sejumlah pelajar bahasa asing, tampaknya sangat menantang. Para pelajar bahasa asing mungkin memiliki kesulitan dalam menulis dengan berbagai alasan, hal tersebut bisa terjadi karena adanya penyebab, sifat, intensitas dan durasi.

McLean (2012) menjelaskan bahwa menulis yang baik itu sulit, bahkan orangorang yang menulis tentang kehidupan pun terkadang perlu berjuang untuk mencapai titik pemikiran yang mereka maksud disetiap halamannya, dan orangorang yang menyukai kegiatan menulis umumnya memiliki hari-hari dimana mereka merasa nyaman untuk melakukannya.

Salah satu cara seorang penulis dapat belajar untuk menulis lebih efektif adalah untuk mempelajari proses menjadi penulis yang sukses. Seorang penulis dapat mempelajari bagaimana penulis yang sukses memulai kegiatan menulis mereka, mengembangkan ide-ide mereka, dan beralih kedalam rancangan akhir. Para penulis harus mengambil strategi agar dapat mengelola diri mereka sendiri menjadi penulis yang baik dan dapat 
FON ; Jurnal Pendidikan Bahasa dan Sastra Indonesia

Volume 12 Nomor 1 Tahun 2018

mengelola berbagai tugas menulis mereka menjadi lebih mudah. Mohite (2014) berpendapat bahwa strategi menulis merupakan alat yang memungkinkan para peserta didik untuk mengendalikan proses menulis mereka, dan mengarah pada peningkatan kepercayaan diri peserta didik sebagai penulis yang independen. Bagaimanapun, para penulis akan menggunakan strategi menulis sepanjang waktu untuk menjaga tulisan mereka tetap baik dan sesuai dengan yang mereka inginkan.

Penulis yang sukses menggunakan mental untuk mengontrol mereka dalam menciptakan suatu tulisan. Bazerman (1985, p.13) menyatakan bahwa strategi yang digunakan dalam menulis akan mengarahkan pada jenis tulisan yang akhirnya ingin ditampilkan, meskipun isinya masih perlu untuk dikembangkan dan rincian bahasanya pun masih perlu untuk diperbaiki. Strategi menulis mencakup strategi menulis bebas, perencanaan, menciptakan ide-ide, menemukan makna, kelompok atau berpasangan, mengingat pembaca, tujuan dan konteks merevisi tulisan, penyusunan dan proofreading (Alnufaie, M., \& Grenfell, M., 2012). Disamping itu, Collins (2008) mengklaim bahwa "menulis yang sebenarnya akan menjadi tugas yang lebih terbatas dalam memilih dan dan menyadari teknik-teknik yang akan digunakan dapat mencapai tujuan. Kita menyebut mental prosedur tersebut sebagai strategi menulis." Jadi, strategi penting bagi para penulis untuk diterapkan dalam kegiatan menulis mereka, hal tersebut dapat membantu mereka membuat tulisan lebih mudah dan menciptakan hasil tulisan yang baik.

Orang-orang menulis agar mencapai tujuan-tujuan yang komunikatif dalam konteks sosial. Kemampuan mereka dalam menulis argumentasi seharusnya menjadi sebuah pengukuran terhadap pemikiran logis yang mereka miliki. Esai argumentatif adalah jenis tulisan yang mengharuskan seorang penulis untuk dapat menyelidiki topik, dan menetapkan posisi mereka terhadap topik yang dibahas secara ringkas (Purdue online writing lab[purdue OWL], 2013). Jadi, untuk menulis esai argumentatif, seseorang perlu kemampuan untuk menganalisa sesuatu yang sedang terjadi dan mengembangkannya pada posisi yang yang mereka pilih. Dalam penelitian ini, peneliti menggunakan esai argumentatif untuk mengetahui strategi menulis yang digunakan oleh Mahasiswa dalam kegiatan menulis mereka. 
Penelitian ini terinspirasi dari beberapa penelitian sebelumnya, seperti penelitian dari Alnufaie, M. \& Grenfell, M. (2012), Asmari (2013), dan Ayele (2015). Pertama, penelitian dari Alnufaie, M. \& Grenfell, M. (2012) menganalisis mengenai strategi menulis L2L lulusan tahun kedua Mahasiswa Saudi yang sedang belajar bahasa Inggris sebagai bahasa asing dan English for Spesific Purposes pada salah satu Perguruan Tinggi Industri Saudi: Jubail Industrial College (JIC). Kedua, penelitian dari Asmari (2013) menganalisis mengenai hubungan antara strategi menulis yang digunakan oleh Mahasiswa universitas yang mempelajari bahasa asing dan kepandaian menulis, hubungan antara penggunaan strategi menulis dan pencapaian Mahasiswa dalam menulis, dan perbedaan antara tinggi rendahnya kekhawatiran Mahasiswa dalam menggunakan strategi. Asmari meneliti 198 Mahasiswa bahasa Inggris (68 pria, dan 130 wanita) di fakultas Seni, Universitas Taif. Ketiga, penelitian dari Ayele (2015) menganalisis tentang efek dari pelatihan dalam belajar metakognitif, afektif dan sosial strategi menulis dalam meningkatkan kemampuan Mahasiswa menggunakan masing-masing dari strategi menulis tersebut.
Bagi orang-orang yang tidak suka menulis atau tidak berpikir bahwa mereka adalah seorang penulis yang baik, tugas dan kegiatan menulis adalah hal yang bisa membuat mereka merasa stress dan bahkan menakutkan. Tidak ada keajaiban ataupun rumus yang membuat kegiatan menulis menjadi lebih cepat dan mudah. Bagaimanapun, para penulis harus menggunakan strategi untuk mengelola diri mereka sendiri menjadi seorang penulis yang baik dan mengelola tugas dan kegiatan menulis mereka lebih baik dan mudah (McLean, 2012). Alasan tersebut meyakinkan kita bahwa untuk menjadi seorang penulis yang sukses, atau untuk melakukan hal yang terbaik didalam setiap kegiatan menulis apapun, dalam hal ini peneliti yakin bahwa para penulis memiliki strategi menulis yang dapat membantu mereka sukses di setiap kegiatan menulis mereka. Oleh karena itu, dalam penelitian ini, peneliti mencoba untuk meneliti strategi menulis yang digunakan oleh para Mahasiswa dalam esai argumentatif, dan menganalisis bagaimana Mahasiswa melakukan strategi menulis sehingga dapat mempengaruhi hasil menulis mereka dalam esai argumentatif.

Strategi menulis disengaja, fokus pada cara berpikir tentang menulis itu 
FON ; Jurnal Pendidikan Bahasa dan Sastra Indonesia

Volume 12 Nomor 1 Tahun 2018

sendiri. Strategi menulis bisa diambil dalam berbagai bentuk. Hal ini bisa dalam sebuah rencana seorang guru yang ingin Mahasiswanya untuk mengikuti kegiatan menulis tentang sebuah laporan, atau sesuatu yang lebih sederhana seperti sebuah trik untuk mengingat bagaimana suatu kata dapat dieja. Alnufaie, M., \& Grenfell, M., (2012) berpendapat bahwa strategi menulis mencakup strategi menulis bebas, perencanaan, menciptakan ide-ide, menemukan makna, kelompok atau berpasangan, mengingat pembaca, tujuan dan konteks merevisi tulisan, penyusunan dan proofreading.

McLean (2012, p. 37) menyebutkan bahwa,

menulis yang baik itu sulit, bahkan orangorang yang menulis tentang kehidupan pun terkadang perlu berjuang untuk mencapai titik pemikiran yang mereka maksud disetiap halamannya, dan orangorang yang menyukai kegiatan menulis umumnya memiliki hari-hari dimana mereka merasa nyaman untuk melakukannya. Bagi orang-orang yang tidak suka menulis atau tidak berpikir bahwa mereka adalah seorang penulis yang baik, tugas dan kegiatan menulis adalah hal yang bisa membuat mereka merasa stress dan bahkan menakutkan. Tidak ada keajaiban ataupun rumus yang membuat kegiatan menulis menjadi lebih cepat dan mudah. Bagaimanapun, para penulis harus menggunakan strategi untuk mengelola diri mereka sendiri menjadi seorang penulis yang baik dan mengelola tugas dan kegiatan menulis mereka lebih baik dan mudah.

Oleh karena itu, menulis dianggap sebagai suatu kegiatan yang kompleks. Sangat penting bagi penulis agar dapat menulis dalam bahasa Inggris, terutama bagi para Mahasiswa. Jadi, mereka harus memiliki beberapa strategi untuk membuat diri mereka lebih mudah dalam kegiatan menulis.

Menurut McLean (2012), ada beberapa strategi menulis yang akan membantu para penulis ataupun para Mahasiswa terutama Mahasiswa perguruan tinggi untuk dapat menyelesaikan tugas menulis mereka dengan baik. Strategi menulis tersebut dibagi menjadi 4 langkah, seperti: menggunakan proses menulis, mengelola waktu, menetapkan tujuan, dan menggunakan sumber pengetahuan yang ada di dalam perguruan tinggi.

Esai argumentatif adalah jenis teks yang menunjukan bahwa penulis memiliki argumen/pendapat yang akurat, dan memungkinkan para pembaca untuk mengikuti posisi penulis 'setuju atau tidak 
FON ; Jurnal Pendidikan Bahasa dan Sastra Indonesia

Volume 12 Nomor 1 Tahun 2018

setuju' terhadap argumen yang dituliskan, dan membujuk para pembaca untuk berpikiran sama dengan apa yang dipikirkan penulis. Dengan kata lain, esai argumentatif adalah jenis tulisan yang mengharuskan seorang penulis untuk dapat menyelidiki topik, dan menetapkan posisi mereka terhadap topik yang dibahas secara ringkas

\section{METODE PENELITIAN}

Dalam penelitian ini peneliti menggunakan metode kualitatif karena penelitian ini menganalisis strategi menulis Mahasiswa yang digunakan dalam esai argumentatif dan mengidentifikasi bagaimana Mahasiswa melakukan strategi menulisnya yang mempengaruhi hasil menulisnya. Peneliti menggunakan metode ini untuk menemukan informasi yang bersangkutan dengan ide/gagasan yang dianalisis pada saat itu. Berikut beberapa pernyataan yang berhubungan dengan penelitian untuk mendukung penelitian ini.

Creswell (2009, p. 4) mengemukakan bahwa penelitian kualitatif bertujuan untuk menyelidiki/memeriksa dan memahami maksud dari individu atau kelompok terhadap masalah sosial. Proses penelitian menyuguhkan pertanyaan-pertanyaan dan langkah-langkah yang muncul, biasanya data dikumpulkan di letak partisipan, data anlisis, dan peneliti membuat penjelasan maksud dari data terseabut.

Penelitian ini dilakukan di program studi pendidikan bahasa Inggris Fakultas Perguruan dan Ilmu Penidikan Universitas Kuningan, yang terletak di desa Sengkahan Jalan Cut Nyak Dien, Kabupaten Kuningan, Jawa Barat.

Dalam pengumpulan data, peneliti memilih 10 Mahasiswa sebagai sumber utama penelitian. Peserta dari penelitian ini adalah Mahasiswa tingkat tiga semester enam program studi pendidikan bahasa Inggris Fakultas Keguruan dan Ilmu Pendidikan Universitas Kuningan. Mereka adalah Mahasiswa yang telah belajar esai argumentatif pada tingkatan kelas sebelumnya, dan mereka dipilih berdasarkan nilai terbaik dalam matakuliah menulis tiga, dan yang mendapatkan nilai terbaik (A) (sangat Memuaskan) hanya terdapat sepuluh orang Mahasiswa.

Data kualitatif dikumpulkan dalam bentuk kata-kata atau gambar-gambar daripada angka (Fraenkel and Wallen, 2009). Dengan kata lain, penelitian kualitatif dikumpulkan dengan menggunakan sifat yang bermacammacam dari teknik kualitatif yang akan 
FON ; Jurnal Pendidikan Bahasa dan Sastra Indonesia

Volume 12 Nomor 1 Tahun 2018

menempatkan penelitian kualitatif. karena mereka termasuk dalam lima Creswell (2012, p. 212) menyebutkan terbaik di kelas mereka yang mendapat bahwa untuk mengumpulkan data poin "A" dalam hal menulis.

kualitatif, peneliti dapat menggunakan

Pertanyaan penelitian pertama beberapa teknik: meneliti, wawancara, difokuskan untuk mengeksplorasi strategi bahan audio, dan dokumen-dokumen dan penulisan yang digunakan oleh EFLlaporan. Berdasarkan metode peserta didik. Strategi penulisan yang pengumpulan data, peneliti menggunakan digunakan dalam penelitian saat ini teknik dokumen dan wawancara.

difokuskan pada empat jenis: menggunakan proses penulisan,

\section{HASIL DAN PEMBAHASAN}

Penelitian ini bertujuan untuk menetapkan tujuan, mengatur waktu, dan menjawab tujuan penelitian; menganalisis strategi penulisan bahasa Inggris yang digunakan, dan mengidentifikasi permasalahan yang dihadapi oleh peserta didik EFL dalam penulisan esai argumentatif. Untuk menjawab tujuan penelitian tersebut, lima mahasiswa/i kelas tiga Jurusan Bahasa Inggris di satu universitas swasta di Jawa Barat dipilih secara purposif berdasarkan pengalaman mereka dalam menulis esai argumentatif di kelas sebelumnya. Mereka dipilih menggunakan sumber daya perguruan tinggi. Data didapat dari sesi wawancara. Untuk mengetahui strategi penulisan yang digunakan oleh siswa, peneliti memberikan pernyataan yang diberikan oleh mahasiswa/i dalam tabel frekuensi strategi penulisan yang digunakan oleh mahasiswa/i dalam penulisan esai argumentatif yang dilampirkan pada Lampiran 1. Kemudian, peneliti merangkum hasil perhitungan strategi penulisan yang digunakan pada gambar 4.1.

\section{JUMLAH STRATEGI PENULISAN DIGUNAKAN OLEH MAHASISWA/I}

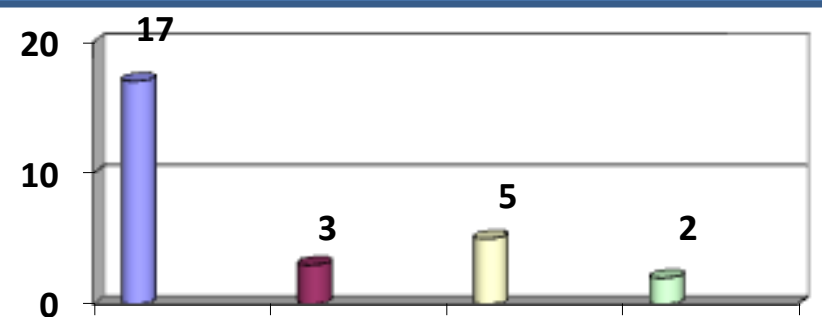

- Mengatur Proses Penulisan -Mengatur Waktu -Menetapkan Tujuan -Mengatur Sumber Kuliah 
FON ; Jurnal Pendidikan Bahasa dan Sastra Indonesia

Volume 12 Nomor 1 Tahun 2018

Strategi yang paling sering digunakan dan mahasiswa/i akan melakukan oleh semua mahasiswa \& mahasiswi segalanya untuk membuat esai tulisan dalam menulis esai argumentatif adalah mereka memiliki hasil yang baik. Ini dengan menggunakan proses penulisan 17 berarti bahwa untuk pertama kalinya (42,5\%), diikuti dengan menetapkan peneliti meminta mereka untuk menulis tujuan $5(12,5 \%)$, mengatur waktu 3 (7, esai argumentatif, mereka harus memiliki $5 \%$ ), dan terakhir menggunakan sumber tujuan untuk tulisan mereka, dan apa yang kuliah 2 (5\%). Penjelasan detail dari mereka lakukan menentukan hasil esai temuan strategi penulisan yang digunakan penulisan mereka. Dalam strategi ini, dalam penelitian ini disajikan pada bagian semua peserta membuat tujuan untuk berikut.

Strategi penulisan yang paling sering tugas menulis mereka, hal itu dibuktikan dengan pernyataan yang diberikan dalam digunakan oleh peserta adalah dengan menggunakan proses penulisan 17 $(42,5 \%)$. Proses penulisan melibatkan beberapa langkah yaitu prapembelajaran (100\%), merevisi (80\%), menguraikan struktur gagasan dan menulis draf kasar yang mendapat persentase sama (60\%), dan pengeditan $(40 \%)$.

Strategi kedua yang paling sering digunakan oleh siswa dalam menulis esai argumentatif adalah menetapkan tujuan 7 $(12,5 \%)$. Melalui penetapan tujuan, para siswa berfokus pada apa yang mereka rencanakan atau yang mereka inginkan dari produk tulisan mereka. Jadi, ketika para mahasiswa/i akan menulis, mereka harus membuat sebuah tujuan untuk apa yang akan mereka tulis untuk membuat apa yang mereka lakukan akan bermanfaat kutipan 76, 10, dan 98.

Strategi yang sering digunakan ketiga oleh mahasiswa/i dalam menulis esai argumentatif adalah mengelola waktu $5(7,5 \%)$. Dengan mengelola waktu, siswa mengatur jadwal mereka secara tertulis, mereka melakukan strategi ini untuk menyelesaikan tugas menulis mereka dengan lebih baik. Dalam mengelola waktu, siswa dapat dikompres dalam beberapa hari atau beberapa jam, mereka dapat menyisihkan waktu untuk mengerjakan tugas menulis mereka, seperti satu untuk pratulis, garis besar, satu untuk penyusunan, dan satu untuk revisi dan editing.

Strategi terakhir yang digunakan oleh mahasiswa/i dalam menulis esai argumentatif adalah dengan menggunakan 
FON ; Jurnal Pendidikan Bahasa dan Sastra Indonesia

Volume 12 Nomor 1 Tahun 2018

sumber daya perguruan tinggi 5\%. penulisan esai argumentatif. Analisis eror Berkaitan dengan penulisan argumentatif, penulisan dan skor masalah penulisan para siswa diminta untuk menggunakan diperoleh dari masing-masing penilai, dan beberapa contoh atau bukti tentang esai ringkasan frekuensi penulisan kesalahan mereka.

Untuk menjawab tujuan penelitian dari para penilai dilampirkan pada pertama yaitu mengidentifikasi masalah lampiran 2. Selain itu, kesalahan diidentifikasi berdasarkan tujuh aspek penulisan yang dihadapi mahasiswa/i (yaitu struktur / organisasi, halaman batas, dalam penulisan esai argumentatif, esai tanda baca, kesimpulan / penutupan, kosa siswa dianalisis. Untuk menganalisis jenis kata, pilihan topik, dan tata bahasa). berbagai kesalahan penulisan dalam esai Gambar 4.1 memberikan ringkasan mahasiswa/i, kesalahan tersebut statistik dari masalah penulisan utama diidentifikasi oleh dua orang penulis yang dicatat dari produk tertulis penulisan. Hasil perhitungan dari para mahasiswa/i yang dianalisis oleh para penilai dicampur untuk mengidentifikasi penilai, dan disusun berdasarkan frekuensi frekuensi masalah penulisan yang mentah yang dimulai dengan frekuensi dihadapi oleh semua mahasiswa/i dalam tertinggi sampai yang paling rendah.

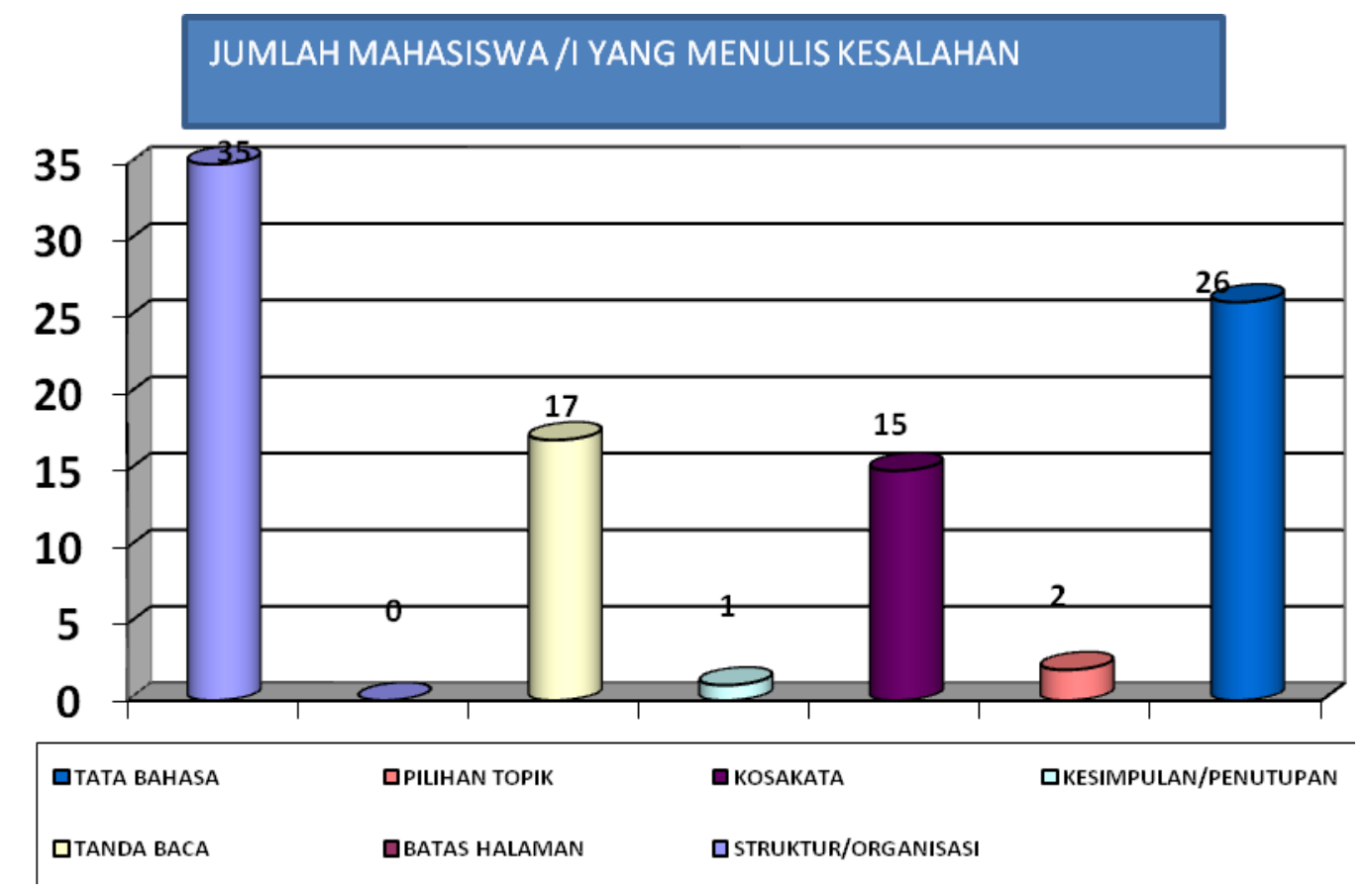

Jumlah Jumlah Kesalahan Penulisan Mahasiswa(i). 
Setelah mengetahui total skor masalah penulisan yang didapat dari produk tulis siswa, dapat diketahui bahwa semua mahasiswa/i menghadapi beberapa masalah dalam penulisan esai argumentatif. Seperti dapat dilihat pada gambar 4.2, struktur atau organisasi dalam menulis esai argumentatif adalah masalah penulisan yang paling umum dihadapi oleh mahasiswa/i 35. Masalah kedua yang paling umum dihadapi mahasiswa/i adalah tata bahasa 26. Setelah itu, diikuti oleh masalah tanda baca 17 , kosa kata 15 , pilihan topik 2, kesimpulan / penutupan 1, dan yang terakhir adalah batas halaman yang tidak memiliki nilai yang ditemukan pada produk tulis mahasiswa/i.

Bagian ini membahas temuan penelitian ini terkait dengan tujuan penelitian. Dalam penelitian ini, strategi penulisan dibagi menjadi 4 kategori, seperti; menggunakan proses penulisan, mengatur waktu, menetapkan tujuan, dan menggunakan sumber daya perguruan tinggi (McLean 2012). Hasil analisis data menunjukkan bahwa siswa menggunakan lebih dari satu strategi dalam penulisan esai argumentatif. Di sisi lain, para siswa menghadapi beberapa masalah penulisan dalam menulis esai mereka. Hasil penelitian menunjukkan bahwa siswa masih mengalami kesulitan dalam bentuk penulisan masalah yaitu struktur / organisasi, batas halaman, tanda baca, kesimpulan / penutupan, kosakata, pemilihan topik, dan tata bahasa (Zhu, 2001).

Tujuan penelitian pertama dari penelitian ini adalah untuk mengidentifikasi strategi penulisan bahasa Inggris yang digunakan oleh peserta didik EFL dalam esai argumentatif dijawab melalui temuan dari gambar 4.1. Gambar 4.1 menunjukkan seringnya strategi penulisan yang digunakan dan mengungkapkan bahwa strategi yang paling sering digunakan di antara empat strategi (dengan menggunakan proses penulisan, pengelolaan waktu, penetapan tujuan, dan penggunaan sumber kuliah) adalah dengan menggunakan proses penulisan 17 (42,5\%), diikuti dengan menetapkan tujuan $5(12,5 \%)$, mengatur waktu $3(7,5 \%)$, dan terakhir menggunakan sumber daya perguruan tinggi $2(5 \%)$. Hasil ini menunjukkan bahwa para siswa tampaknya mengendalikan tulisan mereka. Mereka tahu strategi apa yang berhasil bagi mereka dan mereka menerapkan strategi tersebut secara konsisten. Strategi tersebut digunakan oleh siswa untuk mengatasi 
FON ; Jurnal Pendidikan Bahasa dan Sastra Indonesia

Volume 12 Nomor 1 Tahun 2018

kesulitan mereka saat mereka menulis esai didik EFL dalam penulisan esai argumentatif, dan strategi tersebut argumentatif. Dengan demikian, tujuan membantu mereka menulis dengan mudah dari penelitian ini adalah untuk dan efektif.

Temuan dalam penelitian ini tidak mengidentifikasi masalah penulisan sesuai dengan hasil penelitian argumentatif yang dialami mahasiswa/i sebelumnya. Asmari (2013), yang saat mereka menulis esai argumentatif. berjudul Investigation of Writing Strategies, Writing Apprehension, dan Writing Achievement Among Saudi EFLMajor Students menunjukkan bahwa siswa dengan kecemasan menulis rendah lebih banyak pengguna strategi menulis daripada orang-orang yang cemas. Sementara temuan penelitian yang dilakukan oleh Ayele (2015), yang berjudul pelatihan strategi pembelajaran metakognitif, afektif, dan pembelajaran sosial: pengaruhnya dalam meningkatkan penggunaan strategi oleh mahasiswa/i, kasus mahasiswa Hawassa menunjukkan bahwa pelatihan metakognitif, afektif, dan strategi pembelajaran sosial meningkatkan penggunaan strategi pembelajaran tulisan mahasiswa/i. Dibandingkan dengan temuan penelitian sebelumnya, peneliti menganggap bahwa perbedaan tersebut muncul karena adanya perbedaan objek penelitian ini.

Penelitian kedua dalam penelitian ini adalah untuk mengidentifikasi permasalahan yang dihadapi oleh peserta

Temuan penelitian ini mengungkapkan bahwa kesulitan utama yang dihadapi mahasiswa/i adalah struktur / organisasi, tata bahasa, tanda baca, kosakata, pemilihan topik, batas halaman, dan kesimpulan / penutupan. Masalah ini sejalan dengan Zhu (2001).

Struktur / organisasi telah dianggap sebagai masalah yang paling umum dihadapi oleh mahasiswa/i dalam penulisan esai argumentatif, hal ini memperoleh skor total 35. Masalah kedua yang paling umum dihadapi siswa adalah tata bahasa 26 .

Setelah itu, diikuti dengan masalah tanda baca 17, kosa kata 15, pilihan topik 2, kesimpulan / penutupan 1, dan yang terakhir adalah batas halaman yang tidak memiliki skor kesalahan.

Hasil ini berbeda dengan penelitian sebelumnya yang dilakukan oleh Dee dan Kaur (2014) yang berjudul Difficulties Writing Difficulties of Thai English Major Students, dimana mereka mengungkapkan bahwa kesulitan mahasiswa/i Thailand adalah sebagai berikut: kosa kata, struktur 
FON ; Jurnal Pendidikan Bahasa dan Sastra Indonesia

Volume 12 Nomor 1 Tahun 2018

tata bahasa, memberikan bukti kuat, struktur penulisan argumentatif esai, kendala waktu, pengorganisasian gagasan, pemenuhan kebutuhan tugas, pemahaman pertanyaan, transfer dan penerjemahan L1, dan penulisan laporan tesis.

\section{DAFTAR PUSTAKA}

Akhadiah, Sabarti, Maidar Arsyad dan Sakura Ridwan. 1988. Pembinaan Kemampuan Menulis Bahasa Indonesia. Jakarta: Erlangga

Alnufaie, M., \& Grenfell, M. (2012). EFL students' writing stratefies in Saudi Arabian ESP writing classes: Perspectives on learning strategies in self-access language learning. Studies in Self-Access Learning Journal, 3(4), 407-422. Retrieved from http://sisaljournal.org, on January $13^{\text {th }}, 2017$.

Asmari, A. R. A. (2013). Investigation of writing strategies, writing apprehension, and writing achievement, among Saudi EFLmajor students. International Education Studies, 6(11).

Ayele, Z. A. (2015). Training in metacognitive, affective and social learning strategies of writing: Its effects in improving students' use of the strategies, the case of Hawassa university students. International

Journal of Multidisciplinary Research and Development, 2(7).

Bazerman, C. (1985). The informed writer using sources in the diciplines $\left(2^{\text {nd }}\right.$ ed.). Boston: Houghton Mifflin Company.

Brown, G. (2014). Argumentative esssay. George Brown College: Educational Resources Tutoring and Learning Centre. Retrieved February 19, 2017 from

https://www.georgebrown.ca/upload edFiles/TLC/_documents/Argument ative\%20Essays.pdf

Burns, A. (1999). Collaborative action research for English language teachers. Cambridge University Press.

Burton, J., Quirke, P., Reichmann, C.L., Peyton, J. K. (2009). Reflective writing: A way to lifelong teacher learning. United State of America: TESL-EJ Publications.

Collins, J. L. (2008). Writing strategies. Buffalo: New York. Retrieved from http://gse.buffalo.edu/org/writingstr ategies/, on January $22^{\text {nd }}, 2017$.

Calderonello, A. H. \& Edwards, B. L. (1986). Roughdrafts: The process of writing. Boston: Houghton Mifflin Company. 
FON ; Jurnal Pendidikan Bahasa dan Sastra Indonesia

Volume 12 Nomor 1 Tahun 2018

Celce Murcia Marianne \& Olstain Elite. (2000). Discourse and Contex in Language Teaching.a Guide for Language Teachers. Cambridge : Cambridge University Press

Creswell, J.W. (2009). Research design qualitative, quantitative, and mixed method approaches ( $3^{\text {rd }}$ ed. $)$. London: Sage Publication.

Creswell, J.W. (2012). Educational research planning, conducting, and evaluating quantitative and qualitative research ( $4^{\text {th }} \mathrm{ed}$.). Boston: Pearson.

Emilia, E. (2011). Pendekatan genrebased dalam pengajaran bahasa Inggris: Petunjuk untuk guru. Bandung: RIZQI Press.

Fraenkel, J and Wallen, N. (2009). How to design and evaluate research in education $\left(7^{\text {th }}\right.$ ed.). New York: Mc Graw-Hill.

Gunderson, L. 2009. ESL (ELL)literacy instruction: A guidebook to theory and practice $\left(2^{\text {nd }} E d\right)$. New York and London: Routledge.

Harmer, J. (2007b).The practice of English language teaching ( $4^{\text {th }}$ ed.). Pearson: Longman.

Lodico, M. G., Spaulding, D. T., \& Voegtle, K. H. (2006). Methods in educational research: From theory to practice. San Fransisco: John Wiley \& Sons, Inc.

McLean, S. (2012). Successful writing. Creative Cummons (licensed). Retrieved February 2, 2017, from: 2012books.lardbucket.org/books/suc cessful-writing/

Mohite, M. (2014). An investigation into the English language writing strategies used by EFL secondary school learners (Dissertation, London Metropolitan University, 2014). Retrieved January 5, 2017 from

https://englishagenda.britishcouncil. org/sites/default/files/filefield_paths /an_investigation_into_the_english_ language_writing_strategies_v2.pdf Purdue Online Writing Lab. (2013). Argumentative essay. Retrieved January 5, 2017 from https://owl.english.purdue.edu/owl/r esource/685/05/

Saddler, B. \& Andrade, H. (2004). The writing rubric: Intructional rubrics can help students become selfregulated writers. Educational Leadership.

Smith, C., Sadler, R., Davies, L. (2005). Assessment rubrics. GIHE: Griffifth University. Retrieved February 17, 2017 from 
FON ; Jurnal Pendidikan Bahasa dan Sastra Indonesia

Volume 12 Nomor 1 Tahun 2018

https://www.griffith.edu.au/_data/a Tuan, L.T. (2010). Enhancing EFL ssets/pdf_file/0006/245634/Issueslearners' writing sklill via journal Paper-on-rubrics.pdf writing. English Language

Suriasumantri, Jujun S. 1996.Membangun Teaching, 3(3).

Ilmu dan Teknologi Sejak Dini. Utami, T. A. A. (2014). Improving the Jakarta: Departemen dalam Negri, ability in writing descriptive text Direktorat Jendral Pembangunan through brainstorming technique for Daerah. grade VIII students at SMPN 1 Piyungan (Thesis, Yogyakarta State University, 2014). 